FINAL - accepted by Science, 12 November 2013

\title{
Mars' Surface Radiation Environment Measured with the Mars Science Laboratory's Curiosity Rover
}

Authors: Donald M. Hassler ${ }^{1 *}$, Cary Zeitlin ${ }^{1}$, Robert F. Wimmer-Schweingruber ${ }^{2}$, Bent Ehresmann ${ }^{1}$, Scot Rafkin ${ }^{1}$, Jennifer L. Eigenbrode ${ }^{3}$, David E. Brinza ${ }^{4}$, Gerald Weigle ${ }^{5}$, Stephan Böttcher ${ }^{2}$, Eckart Böhm², Soenke Burmeister ${ }^{2}$, Jingnan Guo ${ }^{2}$, Jan Köhler ${ }^{2}$, Cesar Martin $^{2}$, Guenther Reitz ${ }^{6}$, Francis A. Cucinotta ${ }^{7}$, Myung-Hee Kim ${ }^{8}$, David Grinspoon ${ }^{9}$, Mark A. Bullock ${ }^{1}$, Arik Posner ${ }^{10}$, Javier Gómez-Elvira ${ }^{11}$, Ashwin Vasavada ${ }^{4}$, and John P. Grotzinger $^{4}$, and the MSL Science Team ${ }^{12}$

\section{Affiliations:}

1. Southwest Research Institute, Boulder, CO, USA

2. Christian Albrechts University, Kiel, Germany

3. NASA Goddard Space Flight Center, Greenbelt, MD, USA

4. Jet Propulsion Laboratory, California Institute of Technology, Pasadena, CA, USA

5. Southwest Research Institute, San Antonio, TX, USA

6. German Aerospace Center (DLR), Cologne, Germany

7. University of Nevada Las Vegas, Las Vegas, NV, USA

8. Universities Space Research Association, Houston, TX, USA

9. Denver Museum of Nature \& Science, Denver, CO, USA

10. NASA Headquarters, Washington, DC, USA

11. Centro de Astrobiología (INTA-CSIC), Madrid, Spain

12. See Supplemental Material

*Email: hassler@boulder.swri.edu 


\begin{abstract}
The Radiation Assessment Detector (RAD) on the Mars Science Laboratory's Curiosity rover began making detailed measurements of the cosmic ray and energetic particle radiation environment on the surface of Mars on 7 August 2012. We report and discuss measurements of the absorbed dose and dose equivalent from galactic cosmic rays and solar energetic particles on the Martian surface for $\sim 300$ days of observations during the current solar maximum. These measurements provide insight into the radiation hazards associated with a human mission to the surface of Mars, and provide an anchor point to model the subsurface radiation environment, with implications for microbial survival times of any possible extant or past life, as well as for the preservation of potential organic biosignatures of the ancient Martian environment.
\end{abstract}




\section{Main Text:}

\section{Introduction}

The radiation exposure on the surface of Mars is much harsher than that on the surface of the Earth for two reasons: Mars lacks a global magnetic field to deflect energetic charged particles (1), and the Martian atmosphere is much thinner $(<1 \%)$ than that of Earth, providing little shielding against the high energy particles that are incident at the top of its atmosphere. This environmental factor, for which there is no analog on Earth, poses a challenge for future human exploration of Mars (2-9), and is also important in understanding both geological and potential biological evolution on Mars. The radiation environment on Mars has been previously estimated and modeled (10-17). Here we report in situ measurements of the ionizing radiation environment on the surface of Mars; these can be used to test and validate radiation transport models.

There are two types of energetic particle radiation incident at the top of the Mars atmosphere, Galactic Cosmic Rays (GCRs) and Solar Energetic Particles (SEPs). Both GCRs and SEPs interact with the atmosphere and, if energetic enough, penetrate into the Martian soil, or regolith, where they produce secondary particles (including neutrons and $\gamma$-rays) that contribute to the complex radiation environment on the Martian surface, which is quite unlike that observed at the Earth's surface.

GCRs are high energy particles $(10 \mathrm{MeV} /$ nuc to $>10 \mathrm{GeV} /$ nuc) which are modulated by the heliosphere and anti-correlated with solar activity (18). The composition varies slightly depending on solar modulation, with the proton abundance in the range $85-90 \%$, helium ions $\sim 10-13 \%$, electrons $\sim 1 \%$, and about $1 \%$ heavier nuclei (19-20). Because of their high energies, GCRs are difficult to shield against, and can penetrate up to several meters into the Martian regolith. SEPs are produced in the solar corona as a result of high energy processes associated with flares, coronal mass ejections (CMEs) and their corresponding shocks. SEP events are sporadic and difficult to predict, with onset times on the order of minutes to hours and durations of hours to days. SEP fluxes can vary by 
several orders of magnitude, and are typically dominated by protons, but composition can vary substantially (21). SEP protons and helium ions with ion energies below $\sim 150$ $\mathrm{MeV} / \mathrm{nuc}$ ("soft" spectrum events) are not able to penetrate to the Martian surface. Typical column depths of the Martian atmosphere at Gale Crater are on the order of 20 $\mathrm{g} / \mathrm{cm} 2$, thus energetic particles with energies less than $\sim 150 \mathrm{MeV}$ lose all of their energy before passing through this amount of material. However, during "hard spectrum" events, ions can be accelerated to energies well above $150 \mathrm{MeV} / \mathrm{nuc}$ with substantial fluxes reaching the Martian surface. In all events, secondary neutrons produced by SEPs in the atmosphere can reach the surface. The RAD measurements reported here cover observations of GCRs as well as hard and soft SEP events seen from the Martian surface. Together with the radiation environment results from RAD inside the Mars Science Laboratory (MSL) spacecraft during its cruise to Mars (22), these measurements correspond to all three phases (outbound interplanetary journey, Mars surface stay, and return journey) of a human Mars mission at this time in the solar cycle, and thus are directly relevant to planning for future human missions.

If Martian life exists, or existed in the past, it is reasonable to assume it is or was based on organic molecules (23-24), and will therefore share with terrestrial life the vulnerability to energetic particle radiation (25-26). Thus we present here extrapolations of the RAD surface dose measurements (using transport models) to the Martian subsurface, with implications for estimating lethal depths and microbial survival times (26-30). The radiation environment on Mars may also play a key role in the chemical alteration of the regolith and Martian rocks over geologic time scales, affecting the preservation of organics including potential organic biosignatures of the ancient Martian environment (26-27). The RAD surface measurements provide a baseline for inferring the flux in these more shielded environments (by validating and anchoring transport models), and thus the foundation for understanding the limits to preservation of organic matter in the soil and rocks of Gale Crater. 


\section{Results \& Discussion}

The Curiosity rover landed successfully on Mars in Gale Crater at -4.4 km MOLA (Mars Orbiter Laser Altimeter) altitude on 6 August 2012. On 7 August 2012, the RAD began taking observations of the radiation environment on Mars, incidentally 100 years to the day after the discovery of cosmic rays on Earth by Victor Hess from a balloon in Austria (31). The results reported here are time series of absorbed dose rate, the average absorbed dose rate and average dose equivalent rate, and LET spectra for $\sim 300$ Sols (1 Martian Sol = 24 hrs 39 min.) from Aug. 7, 2012 to June 1, 2013.

Figure 1 shows the radiation dose rate measured by RAD on the Mars surface during the first 300 Sols on Mars, near the maximum of Solar Cycle 24. The GCR dose rate can be seen to vary between 180 and $225 \mu \mathrm{Gy} /$ day, owing to the combined effects of: diurnal variations from atmospheric pressure changes, Mars seasonal variations at Gale Crater and heliospheric structure variability due to solar activity and rotation.

The diurnal dose rates vary by a few percent due to diurnal change in the Mars atmospheric column between Sols 290-302 (Fig. 2a). This diurnal variation of the total atmospheric column mass is related to the daily thermal tides that Mars experiences each Sol, whereby the direct heating of the Martian atmosphere by the Sun produces global scale waves that redistribute atmospheric mass (33). Comparison of the RAD dose rate to the Rover Environment Monitoring Station (REMS) (34) atmospheric pressure measurements shows there is an anti-correlation between total dose rate and atmospheric pressure (Fig. 2b), which in turn is directly related to column depth.

On the Mars surface, during the 300-day period near the maximum of solar cycle 24, we find an average total GCR dose rate at Gale Crater (-4.4 km MOLA) of $0.210+/-0.040$ $\mathrm{mGy} /$ day, compared to $0.48+/-0.08 \mathrm{mGy} /$ day measured during cruise inside the MSL spacecraft (Fig. 3, Table 1). The difference in dose rate is driven by several influences: First, the shielding of the lower hemisphere provided by the planet reduces the dose rate by a factor of $\sim 2$. Second, further deviations from this factor of 2 are due to interactions of primary GCRs with the nucleons in the atmosphere (and soil). Additionally, the effective atmospheric shielding is thicker than the spacecraft shielding of the instrument 
during cruise. The dose rate is also influenced by the modulation of the GCR flux by the sun, i.e. a stronger solar modulation results in overall lower GCR fluxes and thus lower dose rates. The solar modulation parameter during the surface mission to date has been $\sim 577 \mathrm{MV}$, whereas the average $\Phi$ during cruise was $\sim 635 \mathrm{MV}$ (resulting in lower effective GCR flux).

We find the average Quality Factor $<\mathrm{Q}>$ on the Martian surface to be $3.05+/-0.3$, compared with $3.82+/-0.3$ measured during cruise. This smaller $<\mathrm{Q}>$ is due to the thicker shielding in the field of view (FOV) on the surface, because during cruise, approximately half of the RAD FOV was lightly shielded $\left(<10 \mathrm{~g} \mathrm{~cm}^{-2}\right)$ (35). The column depth of the Martian atmosphere averaged about $21 \mathrm{~g} \mathrm{~cm}^{-2}$ over the first 300 sols of Curiosity's mission. Combining the tissue dose rate measurement with $<\mathrm{Q}>$ yields an average GCR dose equivalent rate on the Mars surface of $0.64 \pm 0.12 \mathrm{mSv} /$ day (Fig. 4).

The SEP dose was obtained by subtracting the average GCR dose rate for the duration of the SEP event. It is found to be $50 \mu \mathrm{Gy}$ in the less-shielded of the two detectors used for dosimetry. Because the composition of SEP events (observed both on the surface and during cruise) are dominantly protons, for which $\langle\mathrm{Q}>=\sim 1$, the dose equivalent from this event was about $50 \mu \mathrm{Sv}$, approximately equal to $25 \%$ of the GCR dose equivalent for the one day duration of the event.

The frequency and intensity of SEP events is highly variable and still unpredictable, and although these observations were made near solar maximum, this current solar activity cycle is very weak by historical norms (36). Substantial/ Notable SEP events throughout recent history (February 1956, August 1972, September 1989, etc.) have been reported and modeled to be several orders of magnitude more intense than those currently observed to date by the RAD (37).

Implications for Future Human Missions to Mars. Combining our measurements with those obtained during the cruise phase (22), we estimate a Total Mission dose equivalent of $\sim 1.01 \mathrm{~Sv}$ for a round trip Mars surface mission with 180 days (each way) cruise, and 500 days on the Martian surface for this current solar cycle (Table 2). These mission 
phase durations are based on one possible NASA Design Reference Mission (38); many mission designs and many mission windows at different times in the solar cycle or a different solar cycle would result in somewhat different radiation exposures. Because GCR flux is modulated by solar activity (decreasing during solar activity maximum and increasing during solar activity minimum) and the risk for exposure to SEPs increases with solar activity, the contribution of each to the total mission dose of a future Mars mission depends on when in the solar cycle the mission occurs (3-6).

Estimates of Subsurface Dose Rates. The dose and dose equivalent rates reported in Tables 1 and 2 can be extrapolated to obtain rates below the Martian surface, using the surface measurements to anchor model predictions. Refining estimates of the subsurface radiation environment is important because in-situ regolith-based materials are prime candidates for astronaut shelter shielding materials to reduce or mitigate the biological hazards associated with radiation exposures on future long duration human missions. These improved subsurface radiation estimates give insight into the potential for the preservation of possible organic biosignatures as a function of depth as well as survival times of possible microbial or bacterial life forms left dormant beneath the surface.

Several studies have modeled the expected subsurface radiation regime $(26,39)$, but the dose values depended until now on the modeled radiation environment on the surface. Dartnell et al. (26-27) assumed an absorbed dose of $\sim 150 \mathrm{mGy} / \mathrm{year}$ at the Martian surface, whereas Pavlov et al. (28-29) assumed an absorbed dose of $50 \pm 5 \mathrm{mGy} /$ year. The actual absorbed dose measured by the RAD (76 mGy/yr at the surface; Table 3) allows for more precise estimations of the subsurface dose. Differences may be due in part to differing assumptions in the models about the level of solar modulation compared to the actual level during the measurement period as well as the amount of atmospheric shielding above the surface. Also, all of the above models must assume a rock, ice, or soil density. Based on compositional and morphological observations of the rocks at the John Klein site in Gale Crater (42), we estimate a rock density of $2.8 \mathrm{~g} / \mathrm{cm}^{3}$, which approximates the density of an iron-rich mudstone or siltstone. Although our estimates of subsurface dose depend strongly on the models we used, they are useful for comparison 
purposes. Also note that the natural background radioactivity on present-day Mars is thought to be on the order of $\sim 1 \mu \mathrm{Gy} /$ day (43), suggesting that GCR radiation is no longer the dominant source of radiation below $\sim 3 \mathrm{~m}$. This also implies that the effectiveness of regolith-based shielding materials no longer improves beyond a thickness of $\sim 3$ meters.

Implications for Microbial Survival Times. Energetic particles ionize molecules along their tracks. The energy deposited by ionization or excitation greatly exceeds that required to break many molecular bonds, including those in DNA, other organic molecules and water, thus ionizing radiation is extremely damaging to biomolecules through both direct and indirect mechanisms. Thus, measurements of the surface and subsurface radiation environment are critical for estimating the survival probability and survival times of possible dormant life forms found in the Martian soil, regolith, rock, and ice. For this, the dose rates can be used to calculate the time it would take for different bacterial species to accumulate a lethal dose of radiation in different subsurface depths (44).

Even the radioresistant organism D. radiodurans would, if dormant, be eradicated in the top several meters in a timespan of a few million years (28-29). However, inferred recurring climate changes in the post-Noachian era, due to variations in the planetary obliquity on time scales of several hundred thousand to a few million years (45), could lead to recurring periods of metabolic activity of these otherwise dormant life forms. In this case, it is hypothesized that accumulated radiation damages could be repaired and the "survival clock" of such life forms could be reset to zero for the next dormant phase (26, 28), which could in turn lead to possible survival to present times. It has been (27) estimated that a 2-meter depth drill was necessary to access viable radioresistant cells that may have gone through this reanimation step within 450,000 years. Applying the RAD dose results, we estimate that only a 1-meter depth drill is necessary to access the same viable radioresistant cells. 
Implications for the Preservation of Environmental Records and Organic Biosignatures. Whether the bulk of the Martian atmosphere was lost prior to the Noachian era ( 3.7-4.0 Gy ago), as recent isotope ratio measurements by Curiosity suggest (46), or towards the end of the Noachian era $(39,47-49)$, it is thought that the Martian surface has had little protection from energetic particles for most of its history (50). Over such geologic time scales, an enormous fluence of high energy charged particles (both primary and secondary) has interacted with, and most likely altered, the Martian regolith, contributing substantially to the unique chemistry of the Martian soil and rocks (51-52), and affecting the preservation of environmental records. The assessments of habitability and potential biosignatures of any ancient environment depend on the robustness of the preserved record, and ionizing radiation strongly influences chemical compositions and structures, especially for water, salts, and redox-sensitive components such as organic matter (5356). Carbon isotopic compositions may also be altered in the upper $50 \mathrm{~cm}$ of rock and soil (28). Organic molecules hold high potential for recording biosignatures (57), and organic matter (biogenic or abiogenic) may provide a source of carbon for habitable environments (42). Our RAD surface measurements and subsurface estimates constrain the preservation window for Martian organic matter following exhumation and exposure to ionizing radiation in the top few meters of the Martian surface. Prior studies focused on the top few centimeters of rock, such as that accessible by the MSL drill. Using the amino acid degradation rates observed by (58), Pavlov et al. (29) modeled a $\sim 1000$-fold decrease in 100 amu molecules in $\sim 1$ billion years at $4-5 \mathrm{~cm}$ depth. The higher dose rate to rocks determined by RAD reduces this period to $\sim 650$ million years. They postulated that higher mass molecules would degrade much faster, assuming a molecular chemistry comparable to amino acids. While this assumption is suitable for biomolecules (proteins) of endolithic organisms, it is not representative of Martian biomolecules that survive early diagenesis in sediments, geological organic matter in basalts (59), or exogenously delivered organics (60). Degradation rates for molecules of other organic chemistry are not reported, but survival of organic matter in carbonaceous chondrites demonstrates that meteoritic organic matter survives ionizing radiation for billions of years.

Regardless of the source of Martian organic matter (meteoritic, geological, or biological), its bonds are susceptible to cleavage and radical formation by ionizing charged particle 
radiation. Permanent bond scissions, subsequent cross-linking with other radicals, and volatile formation can occur. Radicals that are formed from cleaved bonds are highly reactive and will react with inorganic and organic chemicals in the immediate environment. In the presence of both radiation and reactive environmental chemicals, organic matter is highly susceptible to alteration and eventual destruction. Irradiation of water and hydroxyl $(-\mathrm{OH})$ groups produces free radicals and molecules $\left(\mathrm{H}+, \mathrm{OH}+, \mathrm{H}_{2} \mathrm{O}_{2}\right)$ that will oxidize hydrocarbons and aromatic macromolecules to produce small organic salts and $\mathrm{CO}_{2}$ via Fenton reactions (61). On Mars, this oxidation process is likely accelerated by the presence of iron mineral catalysts. Further, ionizing radiation plays a key role in the formation of oxychlorine compounds in the atmosphere (62) and ices (63), which have been deposited in sediments (64-66) where they may have undergone radiolysis (52) causing eventual oxidation of any organics by the resulting products.

Although the presence of Martian organic matter has not been confirmed via in situ observation, our RAD measurements suggest that the most favorable conditions for finding evidence of organics on Mars is in rocks or soils that have been more recently exposed (e.g. eroded canyon walls or recent impact craters) and do not show signs of aqueous activity following exhumation.

\section{Materials and Methods}

The RAD instrument (67) consists of a combined charged and neutral particle detector, with a solid state detector telescope, CsI calorimeter, and plastic scintillator for neutron detection. Active coincidence logic discriminates against charged particles entering the detector from outside the charged particles telescope's field of view, and anti-coincidence logic enables detection of neutrons and $\gamma$-rays. The RAD has a wide dynamic range for charged particles and is able to measure all ion species that contribute to the radiation exposure on the surface of Mars with a geometry factor of $\sim 0.9 \mathrm{~cm}^{2}$ sr. The RAD measures differential fluxes of stopping charged particles with energies up to 95 $\mathrm{MeV} /$ nuc for protons and ${ }^{4} \mathrm{He}$, and up to $450 \mathrm{MeV} /$ nuc for ${ }^{56} \mathrm{Fe}$. Neutral particles are identified in the energy range from about $10 \mathrm{MeV}$ to $100 \mathrm{MeV}$. The $\mathrm{dE} / \mathrm{dx}$ resolution of 
the RAD is sufficient to distinguish between major particle species. The RAD measures $\mathrm{dE} / \mathrm{dx}$ in silicon, but these measurements can also be approximately related to Linear Energy Transfer (LET) in water. The RAD dynamic range corresponds to the LET range from 0.2 to $\sim 1000 \mathrm{keV} / \mu \mathrm{m}$ in water.

Dose equivalent is determined by convoluting the Linear Energy Transfer (LET) spectrum of the measured particles with a quality factor, $Q(L)$ (68), that is an approximate measure of biological effectiveness of different radiation types. Dose is a purely physical quantity, with units of Gray or milligray (1 Gray $=1$ joule $/ \mathrm{kg})$. Dose equivalent is dose weighted by a dimensionless biological effectiveness factor which takes into account the energy absorption characteristics of biological tissue, and is expressed in Sieverts or millisieverts.

\section{Observations of SEP Event on 11 April 2013}

Figure 5a shows the dose rate time series associated with the SEP event enhancement seen on 11-12 April 2013 resulting from an M-class flare on the Sun. Although the SEP event appeared relatively weak in terms of flux increase as seen from Earth (GOES-13) (69), its energy spectrum was hard enough to produce an enhancement of $\sim 30 \%$ over the GCR dose rate on the Martian surface. The $40-100 \mathrm{MeV}$ proton flux seen by STEREO-B (70) increased almost 4 orders of magnitude at the peak of this event (Fig 5b). Note that the minimum proton energy required to reach the surface in Gale Crater is about 150 $\mathrm{MeV}$. STEREO-B was leading Mars (in longitude) at the time of the event, and had similar, but not identical, magnetic connection to the Sun. This event was the first "hard spectrum" SEP event seen by RAD on the Mars surface. Because Mars was in solar conjunction at this time, GOES-13 was nearly 180 degrees in heliospheric longitude away, with fluxes of $>50$ and $>100 \mathrm{MeV}$ protons increasing by only two orders of magnitude (Fig. 5c). This SEP event was very broad in heliospheric extent, expanding to greater than 180 degrees in heliographic longitude from the Sun. (Interestingly, this event was not observed by STEREO-A, which was trailing Mars at the time.) These observations from the RAD provide an additional data point to test models of the 3-D structure and propagation of SEPs through the inner heliosphere. 


\section{References and Notes}

(1) Acuna, H.M., et al., 'Magnetic Field and Plasma Observations at Mars: Initial Results of the Mars Global Surveyor Mission', Science (279), 1676-1680, 2013.

(2) Radiation Hazards to Crews on Interplanetary Missions. National Academy of Sciences, Washington, DC, (1996).

(3) Simonsen, L.C., J.E. Nealy, L.W. Townsend, J.W. Wilson. Radiation Exposure for Manned Mars Surface Missions. NASA TP 2979, (1990).

(4) Simonsen, L.C., and J.E. Nealy. Radiation Protection for Human Missions to the Moon and Mars. NASA TP 3079, (1991).

(5) Cucinotta, F. A., Schimmerling, W., Wilson, J. W., Peterson, L. E., Badhwar, G. D., Saganti, P. B. and Dicello, J. F. Space Radiation Cancer Risks and Uncertainties for Mars Missions. Radiat. Res. 156, 682-688 (2001).

(6) Cucinotta, F.A., M. Durante. Cancer risk from exposure to galactic cosmic rays: implications for space exploration by human beings, Lancet Oncol. 7, 431-435 (2006).

(7) Cucinotta, F.A., Chappell, L.J. How Safe is Safe Enough: Radiation Risks for a Human Mission to Mars. PLoS One, (2013a).

(8) Cucinotta, F.A., L. Chappell, M. Y. Kim. Space radiation cancer risk projections and uncertainties - 2012, NASA TP 2013-217375 (2013b).

(9) McKenna-Lawlor, S. P. Goncalves, A. Keating, G. Reitz, D. Matthia. Overview of energetic particle hazards during prospective manned missions to Mars, Planetary \& Space Sci., 63, 123 (2012).

(10) Simonsen, L.C., and J.E. Nealy. Mars Surface Radiation Exposure for Solar Maximum Conditions and 1989 Solar Proton Events. NASA TP 3300, (1993).

(11) Cucinotta, F.A., P.B. Saganti, J.W. Wilson and L.C Simonsen. Model Predictions and Visualization of the Particle Flux on the Surface of Mars, J. Radiation Res. Suppl., 43, S35-39 (2002).

(12) DeAngelis, G., M.S. Clowdsley, R.C. Singleterry, J.W. Wilson. A new Mars Radiation environment model with Visualization, Adv. Space Res., 34, 1328-1332 (2004). 
(13) Saganti, P.B., F.A. Cucinotta, J.W. Wilson, L.C. Simonsen, C. Zeitlin. Radiation Climate Map for Analyzing Risks to Astronauts on the Mars Surface from Galactic Cosmic Rays, Space Sci. Rev. 110, 143-156 (2004).

(14) Cucinotta, F.A., Kim, M.Y.; Schneider, S.I., and Hassler, D.M., Description of light ion production cross sections and fluxes on the Mars surface using the QMSFRG model Radiat Environ Biophys 46, 101-106 (2007).

(15) Kim, M.Y., Hayat, M.L., Feiveson, A.H., and Cucinotta, F.A. Using high-energy proton fluence to improve risk Prediction for consequences of solar particle events. Advances in Space Research 44, 1428-1432, (2009).

(16) Slaba, T.C., Blattnig, S.R., Aghara, S.K., Townsend, L.W., Handler, T., et al. Coupled Neutron Transport for HZETRN. Radiation Measurements 45, 173-182 (2010).

(17) Cucinotta, F.A., Chappell, L.J., Updates to astronaut radiation limits: radiation risks for never-smokers, Radiat. Res. 176, 102-114 (2011).

(18) L.J. Gleeson \& W.I. Axford. Ap. J., 154, 1011 (1968).

(19) Simpson, J. A. Elemental and Isotopic Composition of the Galactic Cosmic Rays, Annual Reviews of Nuclear and Particle Science, 33, 323-381 (1983).

(20) O'Neill, P., Badhwar-O'Neill 2010 galactic cosmic ray flux model - revised, IEEE T. Nucl. Sci. 57, 3148-3153 (2010).

(21) Cane, H.V., I.G. Richardson, T.T. vonRosenvinge. The Properties of Cycle 23 Solar Energetic Proton Events, AIP Conf. Proc. 1216, pp. 687-690 (2010).

(22) Zeitlin, C., D.M. Hassler, F.A. Cucinotta, B. Ehresmann, R.F. WimmerSchweingruber, D.E. Brinza, S. Kang, G. Weigle, S. Bottcher, E. Bohm, S. Burmeister, J. Guo, J. Kohler, C. Martin, A. Posner, S. Rafkin, G. Reitz. Measurements of Energetic Particle Radiation in Transit to Mars on the Mars Science Laboratory, SCIENCE, 340, 1080-1084 (2013).

(23) Pace, N. The universal nature of biochemistry, Proc. Natl. Acad. Sci. 98, 805 (2001).

(24) Grinspoon, D. Lonely Planets: The Natural Philosophy of Alien Life, HarperCollins (2003). 
(25) Dartnell, L., 'Ionizing Radiation and Life.', Astrobiology, vol. 11(6), pp. 551-582, Astrobiology.

(26) Dartnell L, Desorgher L, Ward J, Coates A Modelling the surface and subsurface martian radiation environment: implications for astrobiology. Geophys Res Lett 34:L02207 (2007a).

(27) Dartnell LR, Desorgher L, Ward JM, Coates AJ. Martian sub-surface ionising radiation: biosignatures and geology. Biogeo- sciences 4:545-558 (2007b).

(28) Pavlov, A.K., Blinov, A.V., Konstantinov, A.N.: 2002, 'Sterilization of Martian surface by cosmic radiation', Planet. Space Sci. 50, 669 (2002)

(29) Pavlov, A.K., G. Vasilyev, V.M. Ostryakov, A.K. Pavlov, P. Mahaffy. Degradation of the organic molecules in the shallow subsurface of Mars due to irradiation by cosmic rays, GRL, 39, L13202 (2012).

(30) Schneider, S.I. and J.F. Kasting. Radiation Environments on Mars and their Implications for Terrestrial Planetary Habitability, Bioastronomy 2007: Molecules, Microbes and Extraterrestrial Life, ASP Conf. Series, vol. 420, (2009).

(31) Hess, V.F. "Über Beobachtungen der durchdringenden Strahlung bei sieben Freiballonfahrten". Phys. Zeit., 13, 1084-1091 (1912).

(32) Cane, H. V. Coronal mass ejections and Forbush decreases, Space Sci. Rev., 93, 55- 77 (2000).

(33) Schofield, J.T., Barnes, J.R., Crisp, D., Haberle, R.M., Larsen, S., Magalhães, J.A., Murphy, J.R., Seiff A., and Wilson, G. The Mars Pathfinder Atmospheric Structure Investigation \& Meteorology (ASI/MET) Experiment, Science 278, 1752 (1997).

(34) Gomez-Elvira, J. et al. REMS: The Environmental Sensor Suite for the Mars Science laboratory Rover, Space Sci. Rev., 170, 583-640 (2012).

(35): The larger relative uncertainty in $<Q>$ measured on the surface compared to that in cruise is due to increased uncertainty in the subtraction of the background dose rate coming from Curiosity's radioisotope thermoelectric generator.

(36) Kamide, Y. and K. Kusano. Is Something Wrong With the Present Solar Maximum?, Space Weather, Vol. 11, 140-141 (2013).

(37) Kim, M-H.Y., A.J. Tylka, W.F. Dietrich, F.A. Cucinotta. AGU Meeting, San Francisco, (2012). 
(38) Drake, B.G., S. J. Hoffman, D. W. Beatty, Human Exploration of Mars Design Reference Architecture 5.0, Aerospace Conference, 2010 IEEE, 1-24 (2010).

(39) Ehresmann, B. The Martian Radiation Environment - Early Mars and Future Measurements with the Radiation Assessment Detector, Ph.D. thesis, ChristianAlbrechts-University of Kiel (2012).

(40) HZETRN is the high charge and energy (HZE) transport code developed at NASA Langley Research Center. It computes numerical solutions of the Boltzmann transport equation, accounting for ionization energy loss and nuclear interactions.

(41) Wilson, J.W., et al., 'HZETRN: Description of a Free-Space Ion and Nuclear Transport and Shielding Computer Program', NASA Technical Paper 3495, NASA STI Program, Hampton, VA, 1995.

(42) J.P. Grotzinger, J. Crisp, A.R. Vasavada, R.C. Anderson, C.J. Baker, R. Barry, et al., Mars Science Laboratory Mission and Science Investigation, Space Science Reviews. 170, 5-56 (2012).

(43) Mileikowsky, C., et al., Natural Transfer of Viable Microbes in Space: 1. From Mars to Earth and Earth to Mars, Icarus, 145,391 427, (2000).

(44) Baumstark-Khan, and R. Facius, 2001. Life under Conditions of Ionizing Radiation, in: Astrobiology: The Quest for the Conditions of Life, edited by: Horneck, G. and Baumstark-Khan, C., 260-283, Springer Verlag (2001).

(45) Laskar, J., B. Levrard, \& J. F. Mustard. Orbital forcing of the martian polar layered deposits. Nature, 419, 375-377 (2002).

(46) Webster, C., et al. Science, Vol. 341 no. 6143 pp. 260-263 (2013).

(47) Ehresmann, B., Burmeister, S., Wimmer-Schweingruber, R.-F., Reitz, G. Influence of higher atmospheric pressure on the Martian radiation environment: Implications for possible habitability in the Noachian epoch, JGR, 116, A10,106 (2011).

(48) Kahn, R. The evolution of CO2 on Mars, Icarus, 62, 175-190 (1985).

(49) Lammer, H., W. Stumptner, and G. J. Molina-Cuberos. Martian atmospheric evolution: Implications of an ancient intrinsic magnetic field, Astrobiology: The Quest for the Conditions of Life, pp. 203-217, Springer, Berlin (2002). 
(50) Jakosky, B. and Phillips, R., 'Mars' volatile and climate history.', Nature (412), pp. 237-244, 2001.

(51) Clark, B. C. Geochemical components in Martian soil. Geochemica et Cosmochimica Acta. 57, 4575-4581 (1993).

(52) RC Quinn, HF Martucci, SR Miller, CE Bryson, FJ Grunthaner, PJ Grunthaner. Perchlorate Radiolysis on Mars and the Origin of Martian Soil Reactivity. Astrobiology (2013) vol. 13 (6) pp. 515-520

(53) Court et al. (2007) Raman spectroscopy of irradiated organic matter. Geochim Cosmochim Acta 71:2547-2568

(54) Dartnell et al. Degradation of Cyanobacterial Biosignatures by Ionizing Radiation. Astrobiology (2011) vol. 11 (10) pp. 997-1016

(55) Dartnell et al. Destruction of Raman biosignatures by ionising radiation and the implications for life-detection on Mars. Analytical and Bioanalytical Chemistry (2012) vol. 403 (1) pp. 131-144

(56) Gerakines and Hudson. Glycine's Radiolytic Destruction in Ices: First in situ Laboratory Measurements for Mars. Astrobiology (2013) vol. 13 (7) pp. 647-655

(57) Summons, R.E., J.P. Amend, D. Bish, R. Buick, G.D. Cody, D.J. Des Marais, G. Dromart, J.L. Eigenbrode, A.H. Knoll, D.Y. Sumner. Preservation of Martian Organic and Environmental Records: Final Report of the Mars Biosignature Working Group. Astrobiology, 11, 2 (2011).

(58) Kminek, G. and J. Bada. The effect of ionizing radiation on the preservation of amino acids on Mars, Earth and Planetary Science Letters. 245, 1-5 (2006).

(59) Steele, A., F.M. McCubbin, M. Fries, L. Kater, N.Z. Boctor, M.L. Fogel, et al. A Reduced Organic Carbon Component in Martian Basalts, Science. 337, 212-215 (2012).

(60) Pizzarello, S., G.W. Cooper, G.J. Flynn. The nature and distribution of the organic material in carbonaceous chondrites and interplanetary dust particles, Meteorites and the Early Solar System II. 625-651 (2006).

(61) Benner, S.A. The missing organic molecules on Mars, Proceedings of the National Academy of Sciences. 97, 2425-2430 (2000). 
(62) Catling, D.C., M.W. Claire, K.J. Zahnle, R.C. Quinn, B.C. Clark, M.H. Hecht, et al., Atmospheric origins of perchlorate on Mars and in the Atacama, Journal of Geophysical Research: Solid Earth (1978-2012). 115 (2010).

(63) Hecht, M.H., S.P. Kounaves, R.C. Quinn, S.J. West, S. Young, D.W. Ming, et al., Detection of perchlorate and the soluble chemistry of Martian soil at the Phoenix lander site, Science. 325, 64-67 (2009).

(64) Kim, Y.S., K.P. Wo, S. Maity, S.K. Atreya, R.I. Kaiser, Radiation-Induced Formation of Chlorine Oxides and Their Potential Role in the Origin of Martian Perchlorates, Journal of the American Chemical Society. 135, 4910-4913 (2013).

(65) Glavin, D.P., C. Freissinet, K.E. Miller, J.L. Eigenbrode, A.E. Brunner, A.Buch, B.Sutter, P. D. Archer, Jr., S.K. Atreya, W.B. Brinckerhoff, M. Cabane, P. Coll, P.G. Conrad, D. Coscia, J.P. Dworkin, H.B. Franz, J.P. Grotzinger, L.A. Leshin, M.G. Martin, C. McKay, D.W. Ming, R. Navarro-González, A. Pavlov, A. Steele, R.E. Summons, C. Szopa, S. Teinturier, and P.R. Mahaffy, Evidence for perchlorates and the origin of chlorinated hydrocarbons detected by SAM at the Rocknest aeolian deposit in Gale Crater, JGR-Planets 118, 1-19 (2013)

(66) Leshin, L.A., P.R. Mahaffy, C.R. Webster, M. Cabane, P. Coll, P.G. Conrad, P.D. Archer, Jr., S.K. Atreya, A.E. Brunner, A. Buch, J.L. Eigenbrode, G.J. Flesch, H.B. Franz, C. Freissinet, D.P. Glavin, A.C. McAdam, K.E. Miller, D.W. Ming, R.V. Morris, R. Navarro-González, P.B. Niles, T. Owen, R.O. Pepin, S. Squyres, A. Steele, J.C. Stern, R.E. Summons, D.Y. Sumner, B. Sutter, C. Szopa, S. Teinturier, M.G. Trainer, J.J. Wray, J.P. Grotzinger and the MSL Science Team. Volatile, Isotope and Organic Analysis of Martian Fines with the Mars Curiosity Rover, Science, 341, 6153. (2013).

(67) Hassler, D.M., C.Z. Zeitlin, R.F. Wimmer-Schweingruber, S. Bottcher, C. Martin, J. Andrews, E. Böhm, D. Brinza, M. Bullo ck, S. Burmeister, B. Ehresmann, M. Epperly, D. Grinspoon, J. Köhler, O. Kortmann, K. Neal, J. Peterson, A. Posner, S. Rafkin, L. Seimetz, K. Smith, Y. Tyler, G. Weigle, G. Reitz, and F. Cucinotta. The Radiation Assessment Detector (RAD) Investigation, Space Science Reviews, 170, Issue 1-4, pp. 503-558 (2012).

(68) International Commission on Radiological Protection, 'ICRP Publication 60: 1990 Recommendations of the International Commission on Radiological Protection', Ann. ICRP 21 (1-3), 1991.

(69) Onsager T., et al. Operational uses of the GOES energetic particle detectors, Proc. SPIE 2812, GOES-8 and Beyond, 281 (1996).

(70) Von Rosenvinge T. T., et al. Space Sci. Rev., 136, 391-435 (2008). 


\section{Acknowledgements}

This paper is dedicated to Dr. Michael J. Wargo at NASA HQ, who passed away unexpectedly on August 4, 2013. Mike was Chief Exploration Scientist in the Human Exploration and Operations Mission Directorate (HEOMD), and an enthusiastic supporter of collaborative projects between Science and Exploration. He was a strong supporter of $\mathrm{RAD}$, and a valuable member of both the science and exploration communities. He was a good friend and a wonderful human being, and he will be greatly missed.

RAD is supported by NASA under JPL subcontract \#1273039 to Southwest Research Institute and in Germany by Deutsches Zentrum fur Luft- und Raumfahrt (DLR) and DLR's Space Administration grant numbers 50QM0501 and 50 QM1201 to the Christian Albrechts University, Kiel. Part of this research was carried out at the Jet Propulsion Laboratory, California Institute of Technology, under a contact with the National Aeronautics and Space Administration.

We would like to extend sincere gratitude to Jeff Simmonds and Joy Crisp at JPL, Gale Allen, Michael Meyer, Chris Moore, Victoria Friedensen and Rich Williams at NASA HQ, and Heiner Witte at DLR in Germany for their unwavering support of RAD over the years. The authors would also like to thank the reviewers for their careful and thoughtful comments and suggestions.

The data used in this paper are archived in the NASA Planetary Data System's Planetary Plasma Interactions Node at the University of California, Los Angeles. The archival volume includes the full binary raw data files, detailed descriptions of the structures therein, and higher-level data products in human-readable form. The PPI node is hosted at the following URL: http://ppi.pds.nasa.gov/. 
Figures:

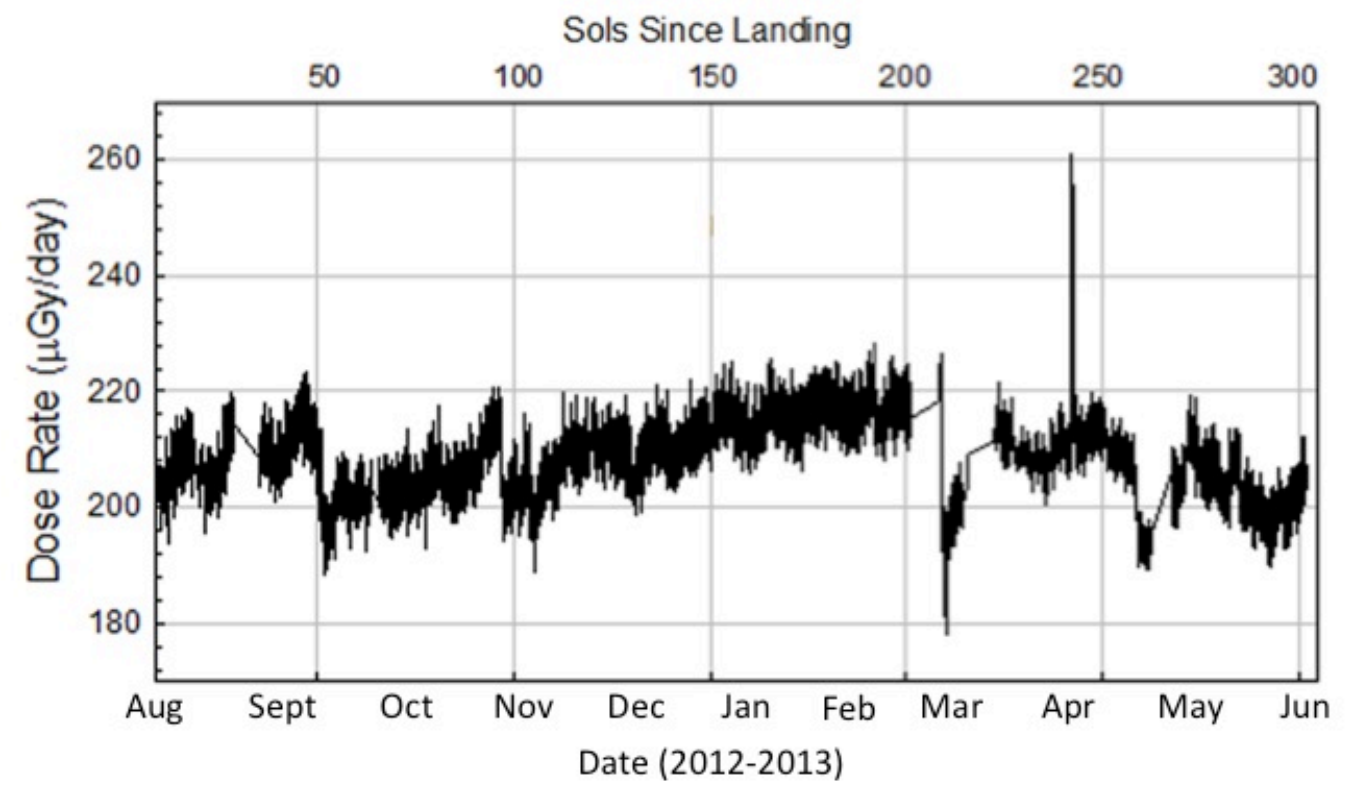

Figure 1. Time series of radiation dose rate measured by RAD on the surface of Mars. During this time, RAD observed a dose rate enhancement from one hard SEP event on Sol 242 (12-13 April 2013), and several Forbush decreases (32), resulting from soft SEP event-related Interplanetary Coronal Mass Ejections (ICMEs) on Sols 50, 97, 208, and 259. (These ICMEs serve as magnetic shields against the GCR, thus reducing the observed flux.) Occasional brief gaps can also be seen, usually caused by RAD having been powered off so that other activities could take place on the spacecraft without interference. 

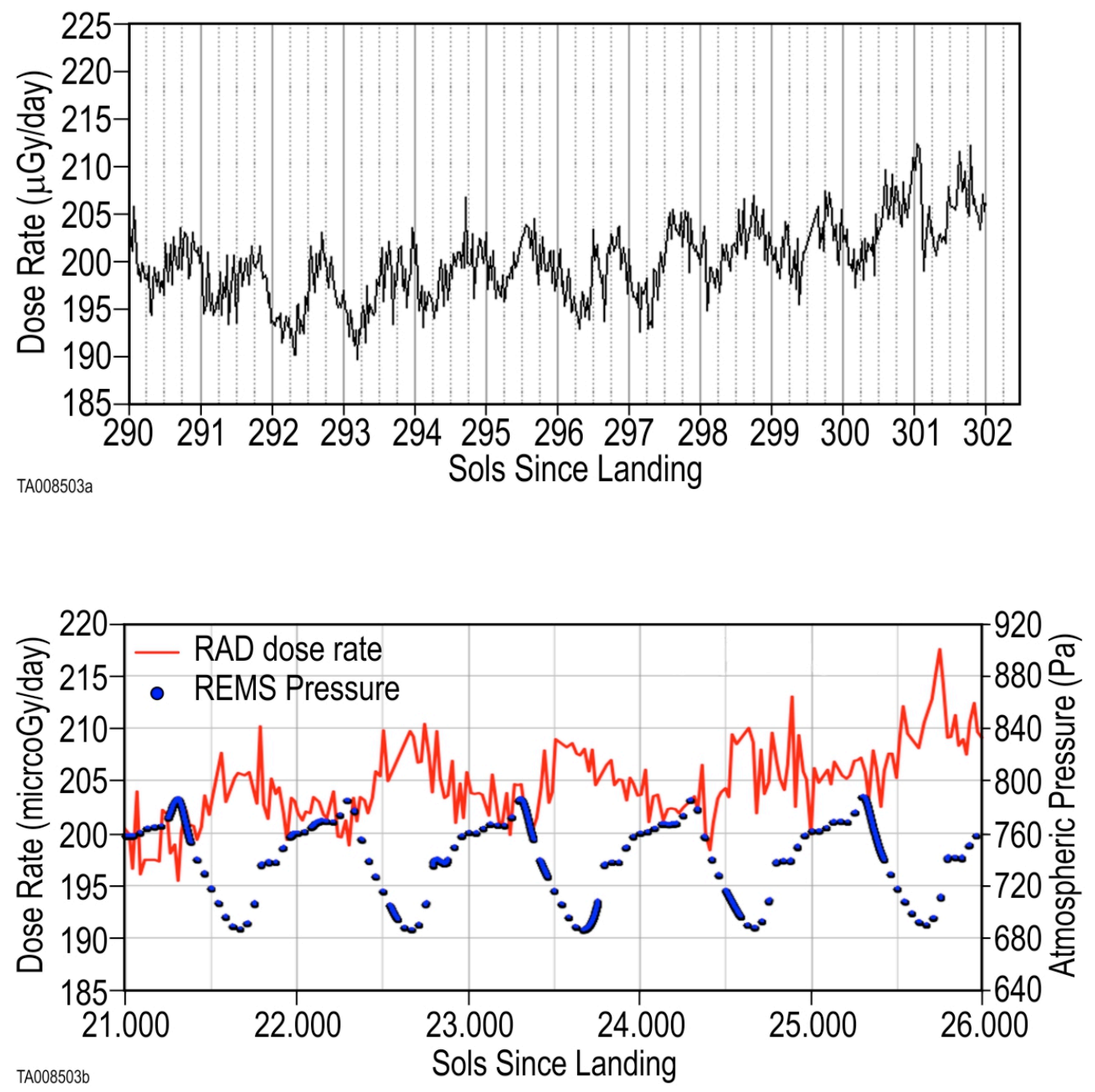

Figure 2. Comparison of RAD dose rate vs time and atmospheric pressure. a) RAD daily dose rate vs time. b) Comparison of RAD dose rate to REMS atmospheric pressure. 


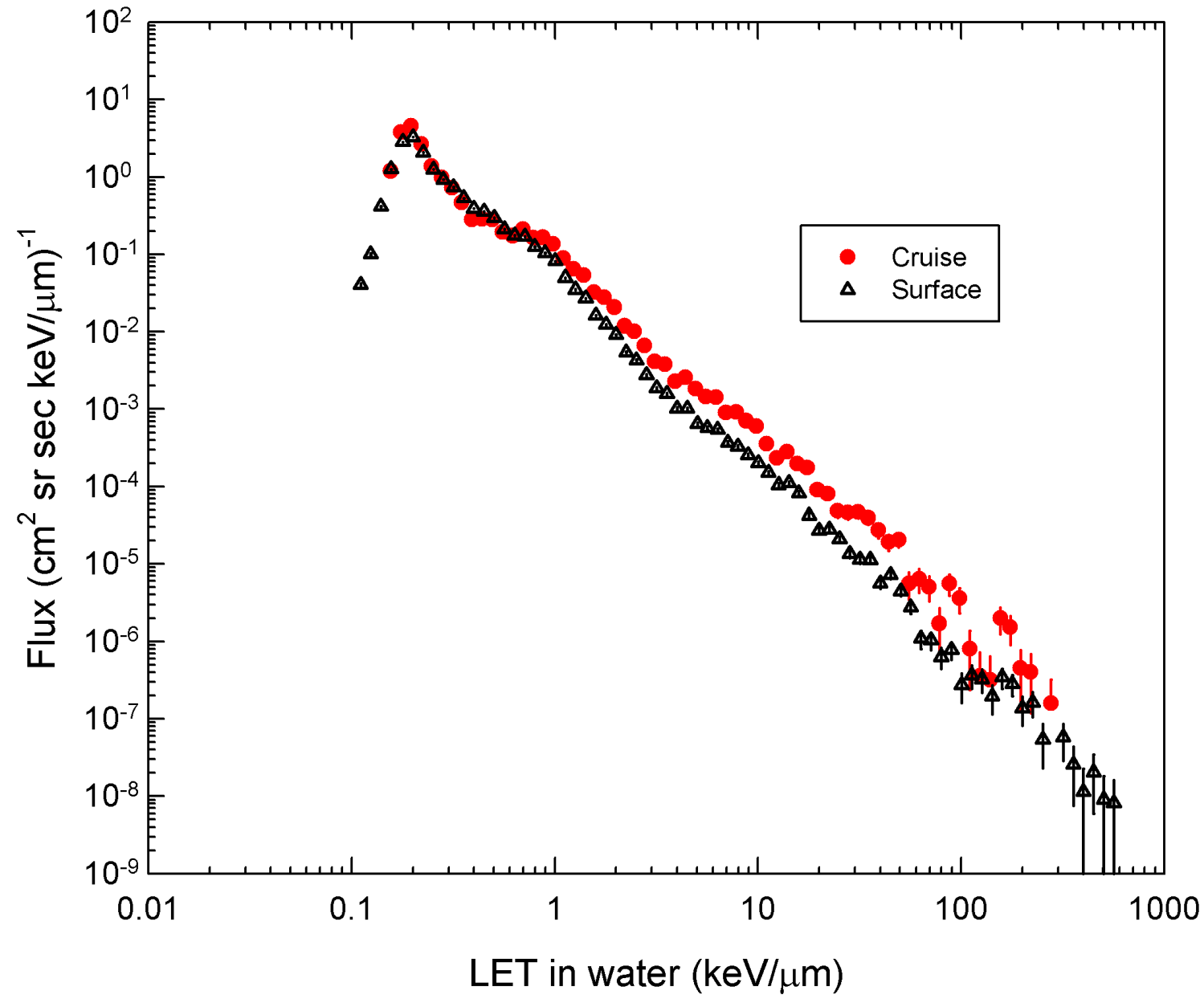

Figure 3. Comparison of charged particle LET spectrum measured on the Mars surface (red) to that measured during cruise inside the MSL spacecraft (black) with variable shielding (22). The energy deposited in silicon has been converted to LET in water. 


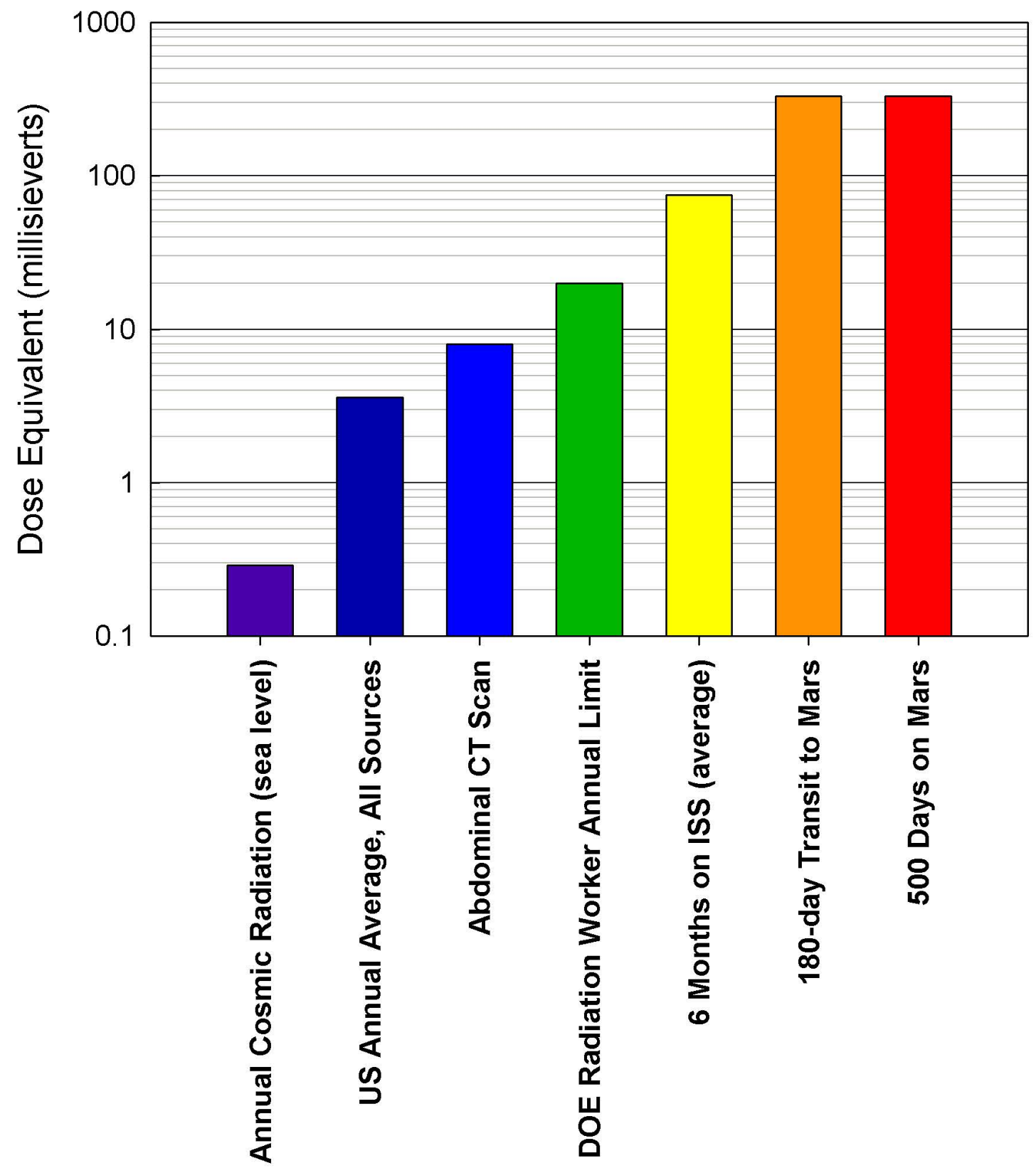

Figure 4: Comparison of the radiation dose equivalent for a 500 day surface stay to that from a 180 day transit to Mars (22), a six month stay on the International Space Station (ISS), and several earth-based sources of radiation. Dose is a purely physical quantity, with units of Gray or milligray (1 Gray $=1$ joule $/ \mathrm{kg}$ ). 

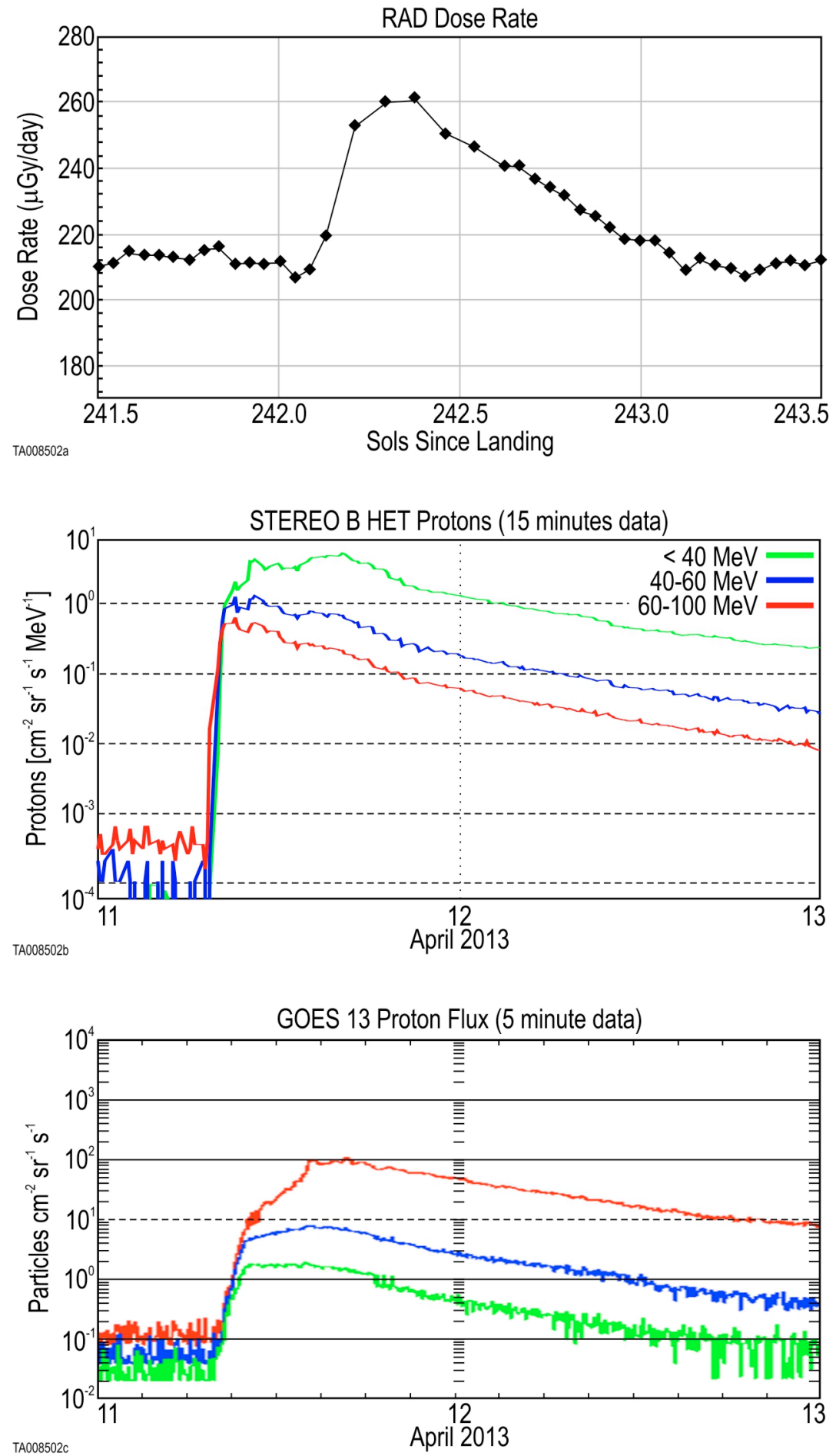

Figure 5. a) Dose rate enhancement from a solar energetic particle (SEP) event observed on the Martian surface by RAD on Sol 242 (11-12 April 2013), while Mars was in solar conjunction. b) the same SEP event seen from the STEREO-B spacecraft, almost magnetically aligned with Mars, and c) The same SEP event seen by the GOES-13 satellite in earth orbit, almost 180 degrees away in heliospheric longitude. 


\section{Tables}

Table 1. Radiation Environment Measured by MSL/RAD (2012-13) (GCR only)

\begin{tabular}{|l|l|l|l|}
\hline RAD Measurement & Mars Surface & MSL Cruise & Units \\
\hline $\begin{array}{l}\text { Charged Particle Flux } \\
\text { (A* B) }\end{array}$ & $0.64 \pm 0.06$ & $1.43 \pm 0.03$ & $\mathrm{~cm}^{-2} \mathrm{~s}^{-1} \mathrm{sr}^{-1}$ \\
\hline Fluence Rate (B) & $1.84 \pm 0.34$ & $3.87 \pm 0.34$ & $\mathrm{~cm}^{-2} \mathrm{~s}^{-1}$ \\
\hline $\begin{array}{l}\text { Dose Rate (Tissue-like) } \\
\text { (E detector) }\end{array}$ & $0.21 \pm 0.04$ & $0.48 \pm 0.08$ & $\mathrm{mGy} /$ day \\
\hline $\begin{array}{l}\text { Avg. Quality Factor }<\mathrm{Q}> \\
\text { Dose Equivalent Rate }\end{array}$ & $3.05 \pm 0.26$ & $3.82 \pm 0.30$ & (dimensionless) \\
\hline $\begin{array}{l}\text { Total Mission Dose Equivalent } \\
\text { (NASA Design Reference } \\
\text { Mission, DRM) }\end{array}$ & $\begin{array}{l}320 \pm 50 \\
(500 \text { days })\end{array}$ & $\begin{array}{l}662 \pm 108 \\
(2 \times 180 \text { days })\end{array}$ & $\mathrm{mSv}$ \\
\hline
\end{tabular}

Charged particle fluxes for both cruise and surface were calculated using the singleended geometric factor for a two-detector coincidence $\left(0.90 \mathrm{~cm}^{2} \mathrm{sr}\right)$. Fluence rates were calculated using all hits above threshold in a single detector (B, with area 1.92 $\mathrm{cm}^{2}$ ). Solar modulation was, on average, slightly stronger during the first 300 sols on the surface than during cruise. 
Table 2: Mars Radiation Environment Summary during 2012-13 Solar Maximum (GCR \& SEP). The GCR dose rates are per day and the SEP doses are per event, showing a range from the sampling of 5 (medium-size) SEP events observed during cruise and the 1 (small) event observed on the surface. Although the one SEP event observed on the Martian surface was small, it is our only statistical sampling to date (see Materials and Methods).

\begin{tabular}{|c|c|c|c|c|}
\hline & $\begin{array}{c}\text { GCR Dose Rate } \\
\text { (mGy/day) }\end{array}$ & $\begin{array}{c}\text { GCR Dose } \\
\text { Equiv. Rate } \\
\text { (mSv/day) }\end{array}$ & $\begin{array}{c}\text { SEP Dose } \\
\text { (mGy/event) }\end{array}$ & $\begin{array}{c}\text { SEP Dose } \\
\text { Equivalent } \\
\text { (mSv/event) }\end{array}$ \\
\hline $\begin{array}{c}\text { MSL Cruise } \\
\text { (Zeitlin et al. 2013) } \\
\text { (22) }\end{array}$ & 0.464 & 1.84 & $1.2-19.5^{\mathrm{a}}$ & $1.2-19.5$ \\
\hline Mars Surface & 0.210 & 0.64 & $0.025^{\mathrm{b}}$ & 0.025 \\
\hline
\end{tabular}

Table 3: Mars Subsurface Radiation Estimates (scaled to RAD Surface Measurements). Both subsurface dose estimates and dose equivalent rated were determined by scaling HZETRN model $(40,41)$ calculations to RAD surface measurement values (Table 2).

\begin{tabular}{|c|c|c|c|}
\hline $\begin{array}{l}\text { Depth below } \\
\text { Surface }\end{array}$ & $\begin{array}{c}\text { Effective } \\
\text { Shielding } \\
\text { mass (g/cm²) }\end{array}$ & $\begin{array}{l}\text { GCR Dose } \\
\text { Rate } \\
\text { (mGy/yr) }\end{array}$ & $\begin{array}{l}\text { GCR Dose } \\
\text { Equiv. Rate } \\
\text { (mSv/yr) }\end{array}$ \\
\hline $\begin{array}{c}\text { Mars Surface } \\
\text { (RAD) }\end{array}$ & 0 & 76 & 232 \\
\hline$-10 \mathrm{~cm}$ & 28 & 96 & 295 \\
\hline$-1 \mathrm{~m}$ & 280 & 36.4 & 81 \\
\hline$-2 \mathrm{~m}$ & 560 & 8.7 & 15 \\
\hline$-3 \mathrm{~m}$ & 840 & 1.8 & 2.9 \\
\hline
\end{tabular}




\section{Supplemental Material}

Mars Science Laboratory (MSL) Science Team

\section{Aalto University}

Osku Kemppinen

Applied Physics Laboratory (APL) at Johns Hopkins University

Nathan Bridges, Jeffrey R. Johnson, Michelle Minitti

Applied Research Associates, Inc. (ARA)

David Cremers

Arizona State University (ASU)

James F. Bell III, Lauren Edgar, Jack Farmer, Austin Godber, Meenakshi Wadhwa, Danika Wellington

\section{Ashima Research}

Ian McEwan, Claire Newman, Mark Richardson

\section{ATOS Origin}

Antoine Charpentier, Laurent Peret

Australian National University (ANU)

Penelope King

Bay Area Environmental Research Institute (BAER)

Jennifer Blank

Big Head Endian LLC

Gerald Weigle

Brock University

Mariek Schmidt

Brown University

Shuai Li, Ralph Milliken, Kevin Robertson, Vivian Sun

California Institute of Technology (Caltech)

Michael Baker, Christopher Edwards, Bethany Ehlmann, Kenneth Farley, Jennifer Griffes, John Grotzinger, Hayden Miller, Megan Newcombe, Cedric Pilorget, Melissa Rice, Kirsten Siebach, Katie Stack, Edward Stolper 


\section{Canadian Space Agency (CSA)}

Claude Brunet, Victoria Hipkin, Richard Léveillé, Geneviève Marchand, Pablo Sobrón

Sánchez

\section{Capgemini France}

Laurent Favot

Carnegie Institution of Washington

George Cody, Andrew Steele

Carnegie Mellon University

Lorenzo Flückiger, David Lees, Ara Nefian

Catholic University of America

Mildred Martin

Centre National de la Recherche Scientifique (CNRS)

Marc Gailhanou, Frances Westall, Guy Israël

Centre National d'Etudes Spatiales (CNES)

Christophe Agard, Julien Baroukh, Christophe Donny, Alain Gaboriaud, Philippe

Guillemot, Vivian Lafaille, Eric Lorigny, Alexis Paillet, René Pérez, Muriel Saccoccio,

Charles Yana

Centro de Astrobiología (CAB)

Carlos Armiens-Aparicio, Javier Caride Rodríguez, Isaías Carrasco Blázquez, Felipe Gómez Gómez, Javier Gómez-Elvira, Sebastian Hettrich, Alain Lepinette Malvitte, Mercedes Marín Jiménez, Jesús Martínez-Frías, Javier Martín-Soler, F. Javier MartínTorres, Antonio Molina Jurado, Luis Mora-Sotomayor, Guillermo Muñoz Caro, Sara Navarro López, Verónica Peinado-González, Jorge Pla-García, José Antonio Rodriguez Manfredi, Julio José Romeral-Planelló, Sara Alejandra Sans Fuentes, Eduardo Sebastian Martinez, Josefina Torres Redondo, Roser Urqui-O'Callaghan, María-Paz Zorzano Mier

\section{Chesapeake Energy}

Steve Chipera

Commissariat à l'Énergie Atomique et aux Énergies Alternatives (CEA)

Jean-Luc Lacour, Patrick Mauchien, Jean-Baptiste Sirven

\section{Concordia College}

Heidi Manning

Cornell University

Alberto Fairén, Alexander Hayes, Jonathan Joseph, Steven Squyres, Robert Sullivan,

Peter Thomas 
CS Systemes d'Information

Audrey Dupont

Delaware State University

Angela Lundberg, Noureddine Melikechi, Alissa Mezzacappa

\section{Denver Museum of Nature \& Science}

David Grinspoon

Deutsches Zentrum für Luft- und Raumfahrt (DLR)

Günther Reitz, Thomas Berger, Daniel Matthia

eINFORMe Inc. (at NASA GSFC)

Benito Prats

Finnish Meteorological Institute

Evgeny Atlaskin, Maria Genzer, Ari-Matti Harri, Harri Haukka, Henrik Kahanpää, Janne

Kauhanen, Osku Kemppinen, Mark Paton, Jouni Polkko, Walter Schmidt, Tero Siili

\section{GeoRessources}

Cécile Fabre

Georgia Institute of Technology

James Wray, Mary Beth Wilhelm

Géosciences Environnement Toulouse (GET)

Franck Poitrasson

Global Science \& Technology, Inc.

Kiran Patel

Honeybee Robotics

Stephen Gorevan, Stephen Indyk, Gale Paulsen

Imperial College

Sanjeev Gupta

Indiana University Bloomington

David Bish, Juergen Schieber

Institut d'Astrophysique Spatiale (IAS)

Brigitte Gondet, Yves Langevin 
Institut de Chimie des Milieux et Matériaux de Poitiers (IC2MP)

Claude Geffroy

Institut de Recherche en Astrophysique et Planétologie (IRAP), Université de Toulouse

David Baratoux, Gilles Berger, Alain Cros, Claude d'Uston, Olivier Forni, Olivier Gasnault, Jérémie Lasue, Qiu-Mei Lee, Sylvestre Maurice, Pierre-Yves Meslin, Etienne Pallier, Yann Parot, Patrick Pinet, Susanne Schröder, Mike Toplis

Institut des Sciences de la Terre (ISTerre)

Éric Lewin

inXitu

Will Brunner

Jackson State University

Ezat Heydari

Jacobs Technology

Cherie Achilles, Dorothy Oehler, Brad Sutter

Laboratoire Atmosphères, Milieux, Observations Spatiales (LATMOS)

Michel Cabane, David Coscia, Guy Israël, Cyril Szopa

Laboratoire de Géologié de Lyon : Terre, Planète, Environnement (LGL-TPE)

Gilles Dromart

Laboratoire de Minéralogie et Cosmochimie du Muséum (LMCM)

François Robert, Violaine Sautter

Laboratoire de Planétologie et Géodynamique de Nantes (LPGN)

Stéphane Le Mouélic, Nicolas Mangold, Marion Nachon

Laboratoire Génie des Procédés et Matériaux (LGPM)

Arnaud Buch

Laboratoire Interuniversitaire des Systèmes Atmosphériques (LISA)

Fabien Stalport, Patrice Coll, Pascaline François, François Raulin, Samuel Teinturier

Lightstorm Entertainment Inc.

James Cameron 


\section{Los Alamos National Lab (LANL)}

Sam Clegg, Agnès Cousin, Dorothea DeLapp, Robert Dingler, Ryan Steele Jackson, Stephen Johnstone, Nina Lanza, Cynthia Little, Tony Nelson, Roger C. Wiens, Richard B. Williams

\section{Lunar and Planetary Institute (LPI)}

Andrea Jones, Laurel Kirkland, Allan Treiman

\section{Malin Space Science Systems (MSSS)}

Burt Baker, Bruce Cantor, Michael Caplinger, Scott Davis, Brian Duston, Kenneth Edgett, Donald Fay, Craig Hardgrove, David Harker, Paul Herrera, Elsa Jensen, Megan R. Kennedy, Gillian Krezoski, Daniel Krysak, Leslie Lipkaman, Michael Malin, Elaina McCartney, Sean McNair, Brian Nixon, Liliya Posiolova, Michael Ravine, Andrew Salamon, Lee Saper, Kevin Stoiber, Kimberley Supulver, Jason Van Beek, Tessa Van Beek, Robert Zimdar

Massachusetts Institute of Technology (MIT)

Katherine Louise French, Karl Iagnemma, Kristen Miller, Roger Summons

\section{Max Planck Institute for Solar System Research}

Fred Goesmann, Walter Goetz, Stubbe Hviid

\section{Microtel}

Micah Johnson, Matthew Lefavor, Eric Lyness

Mount Holyoke College

Elly Breves, M. Darby Dyar, Caleb Fassett

\section{NASA Ames}

David F. Blake, Thomas Bristow, David DesMarais, Laurence Edwards, Robert Haberle, Tori Hoehler, Jeff Hollingsworth, Melinda Kahre, Leslie Keely, Christopher McKay, Mary Beth Wilhelm

\section{NASA Goddard Space Flight Center (GSFC)}

Lora Bleacher, William Brinckerhoff, David Choi, Pamela Conrad, Jason P. Dworkin, Jennifer Eigenbrode, Melissa Floyd, Caroline Freissinet, James Garvin, Daniel Glavin, Daniel Harpold, Andrea Jones, Paul Mahaffy, David K. Martin, Amy McAdam, Alexander Pavlov, Eric Raaen, Michael D. Smith, Jennifer Stern, Florence Tan, Melissa Trainer

NASA Headquarters

Michael Meyer, Arik Posner, Mary Voytek 


\section{NASA Jet Propulsion Laboratory (JPL)}

Robert C, Anderson, Andrew Aubrey, Luther W. Beegle, Alberto Behar, Diana Blaney, David Brinza, Fred Calef, Lance Christensen, Joy A. Crisp, Lauren DeFlores, Bethany Ehlmann, Jason Feldman, Sabrina Feldman, Gregory Flesch, Joel Hurowitz, Insoo Jun, Didier Keymeulen, Justin Maki, Michael Mischna, John Michael Morookian, Timothy Parker, Betina Pavri, Marcel Schoppers, Aaron Sengstacken, John J. Simmonds, Nicole Spanovich, Manuel de la Torre Juarez, Ashwin R. Vasavada, Christopher R. Webster, Albert Yen

NASA Johnson Space Center (JSC)

Paul Douglas Archer, Francis Cucinotta, John H. Jones, Douglas Ming, Richard V. Morris, Paul Niles, Elizabeth Rampe

\section{Nolan Engineering}

Thomas Nolan

\section{Oregon State University}

Martin Fisk

\section{Piezo Energy Technologies}

Leon Radziemski

\section{Planetary Science Institute}

Bruce Barraclough, Steve Bender, Daniel Berman, Eldar Noe Dobrea, Robert Tokar, David Vaniman, Rebecca M. E. Williams, Aileen Yingst

\section{Princeton University}

Kevin Lewis

\section{Rensselaer Polytechnic Institute (RPI)}

Laurie Leshin

\section{Retired}

Timothy Cleghorn, Wesley Huntress, Gérard Manhès

\section{Salish Kootenai College}

Judy Hudgins, Timothy Olson, Noel Stewart

Search for Extraterrestrial Intelligence Institute (SETI I)

Philippe Sarrazin

\section{Smithsonian Institution}

John Grant, Edward Vicenzi, Sharon A. Wilson 


\section{Southwest Research Institute (SwRI)}

Mark Bullock, Bent Ehresmann, Victoria Hamilton, Donald M. Hassler, Joseph Peterson, Scot Rafkin, Cary Zeitlin

Space Research Institute

Fedor Fedosov, Dmitry Golovin, Natalya Karpushkina, Alexander Kozyrev, Maxim Litvak, Alexey Malakhov, Igor Mitrofanov, Maxim Mokrousov, Sergey Nikiforov, Vasily Prokhorov, Anton Sanin, Vladislav Tretyakov, Alexey Varenikov, Andrey

Vostrukhin, Ruslan Kuzmin

Space Science Institute (SSI)

Benton Clark, Michael Wolff

State University of New York (SUNY) Stony Brook

Scott McLennan

Swiss Space Office

Oliver Botta

TechSource

Darrell Drake

Texas A\&M

Keri Bean, Mark Lemmon

The Open University

Susanne P. Schwenzer

United States Geological Survey (USGS) Flagstaff

Ryan B. Anderson, Kenneth Herkenhoff, Ella Mae Lee, Robert Sucharski

Universidad de Alcalá

Miguel Ángel de Pablo Hernández, Juan José Blanco Ávalos, Miguel Ramos

Universities Space Research Association (USRA)

Myung-Hee Kim, Charles Malespin, Ianik Plante

University College London (UCL)

Jan-Peter Muller

University Nacional Autónoma de México (UNAM)

Rafael Navarro-González

University of Alabama

Ryan Ewing 


\section{University of Arizona}

William Boynton, Robert Downs, Mike Fitzgibbon, Karl Harshman, Shaunna Morrison

University of California Berkeley

William Dietrich, Onno Kortmann, Marisa Palucis

University of California Davis

Dawn Y. Sumner, Amy Williams

\section{University of California San Diego}

Günter Lugmair

University of California San Francisco

Michael A. Wilson

University of California Santa Cruz

David Rubin

University of Colorado Boulder

Bruce Jakosky

\section{University of Copenhagen}

Tonci Balic-Zunic, Jens Frydenvang, Jaqueline Kløvgaard Jensen, Kjartan Kinch, Asmus Koefoed, Morten Bo Madsen, Susan Louise Svane Stipp

University of Guelph

Nick Boyd, John L. Campbell, Ralf Gellert, Glynis Perrett, Irina Pradler, Scott VanBommel

University of Hawai'i at Manoa

Samantha Jacob, Tobias Owen, Scott Rowland

University of Helsinki

Evgeny Atlaskin, Hannu Savijärvi

University of Kiel

Eckart Boehm, Stephan Böttcher, Sönke Burmeister, Jingnan Guo, Jan Köhler, César

Martín García, Reinhold Mueller-Mellin, Robert Wimmer-Schweingruber

University of Leicester

John C. Bridges

University of Maryland

Timothy McConnochie 


\section{University of Maryland Baltimore County}

Mehdi Benna, Heather Franz

University of Maryland College Park

Hannah Bower, Anna Brunner

University of Massachusetts

Hannah Blau, Thomas Boucher, Marco Carmosino

University of Michigan Ann Arbor

Sushil Atreya, Harvey Elliott, Douglas Halleaux, Nilton Rennó, Michael Wong

University of Minnesota

Robert Pepin

University of New Brunswick

Beverley Elliott, John Spray, Lucy Thompson

University of New Mexico

Suzanne Gordon, Horton Newsom, Ann Ollila, Joshua Williams

University of Queensland

Paulo Vasconcelos

University of Saskatchewan

Jennifer Bentz

University of Southern California (USC)

Kenneth Nealson, Radu Popa

University of Tennessee Knoxville

Linda C. Kah, Jeffrey Moersch, Christopher Tate

University of Texas at Austin

Mackenzie Day, Gary Kocurek

University of Washington Seattle

Bernard Hallet, Ronald Sletten

University of Western Ontario

Raymond Francis, Emily McCullough

University of Winnipeg

Ed Cloutis 


\section{Utrecht University}

Inge Loes ten Kate

\section{Vernadsky Institute}

Ruslan Kuzmin

Washington University in St. Louis (WUSTL)

Raymond Arvidson, Abigail Fraeman, Daniel Scholes, Susan Slavney, Thomas Stein, Jennifer Ward

\section{Western University}

Jeffrey Berger

\section{York University}

John E. Moores 